\title{
Interview
}

\section{An interview with Dr. Jasone Cenoz on multilingual education and translanguaging}

\author{
Núria Hernández-Castillo \\ Universitat Internacional de Catalunya, Barcelona, Spain
}

Text received 21 October 2015; final version 12 November 2015

DOI: http://dx.doi.org/10.5565/rev/jtl3.658

Dr. Jasone Cenoz is Professor of Applied Linguistics in the Department of Research Methods at the University of the Basque Country. Her research interests include multilingual education, the acquisition of English as a third language, language learning in school contexts and minority languages. She has also conducted research on Basque multilingual education and translanguaging in written production.

Her work has been published in different scientific journals, including The Modern Language Journal, TESOL Quarterly, Language Teaching, Applied Linguistics, Language Culture and Curriculum, The International Journal of Bilingual Education and Bilingualism, and The International Journal of Multilingualism, which she founded along with Dr. Ulrike Jessner and which she edited for eight years. She has also edited a number of books, such as the recently published Multilingual Education: Between Language Learning and Translanguaging (Cambridge University Press, 2015) together with Dr. Durk Gorter. Cenoz is also the author of several book chapters and books, including Towards Multilingual Education (Multilingual Matters, 2009), for which she was awarded the Prize for Excellence in Research by the Spanish Association of Applied Linguistics (AELA).

After having been a member of several international associations for many years, Dr. Cenoz is the current president of the International Association of Multilingualism and the coordinator of the European Master's in Mulitlingualism and Education at the University of the Basque Country.

The interview published in this issue was conducted in the autumn of 2015 as part of the meetings held with regard to the author's doctoral thesis and research interests during a brief stay in Donostia (Spain). This interview brings forward some key aspects of multilingual education from the perspective of an expert in this particular field.

\section{Interview}

Interviewer: For decades, learning a foreign language at school has been common practice in many educational systems. However, multilingual education has been explored more recently as a concept. What has changed?

Jasone Cenoz: I think that one factor is the importance of English, and the fact that it is not enough to have two or three hours of English per week in schools. There are important factors that suggest that we have to go for multilingual education instead of teaching a language for two or three hours per week. Another reason is that the terms 'bilingual' and 'bilingual education' have negative connotations in the United States. Nowadays there are more publications that mention multilingualism and multilingual education rather than bilingualism and bilingual education, and that is always linked to political problems and it is also linked to the fact that there has been a lot of controversy over the use of Spanish and English in the 
classroom. So it is the idea that nowadays multilingualism is sometimes used to refer to bilingualism but it has been deemed to be a better concept. Therefore, I would say there are two main reasons. One is that we should move from teaching a foreign language for just two or three hours a week to implementing a multilingual programme and the other is 'bilingualism' used as a label, which is being gradually replaced by 'multilingualism'.

Interviewer: So would you say that multilingualism is more inclusive?

Jasone Cenoz: Well it's more inclusive in that it can usually refer to two or more languages. Bilingualism only refers to two languages by definition and nowadays we go beyond two languages in many cases. For example, within immigrant populations, with minority languages or when learning additional foreign languages, we have to look at the speakers' whole repertoire and not only at two specific languages. In that sense, it is more inclusive.

Interviewer: What are the main challenges of multilingual education at present?

Jasone Cenoz: There are many challenges. One is to find a balance in the different languages used in this educational approach. Multilingual education is becoming a synonym for teaching and learning English and through English. I mean, we teach English and we call it multilingual. Well, there are many different languages and we have to find different models and different balances, depending on the context. There are also other challenges if we look at the languages in the curriculum. We need to find ways in which we could work with those different languages if we had a unified curriculum, or rather curricula, instead of keeping languages in separate boxes. Those could be some of the challenges but there are many more, of course.

Interviewer: Are teachers ready to face those challenges?

Jasone Cenoz: It depends. Some teachers might be ready and others might not. One of the problems that we have also been facing with the early introduction of English, for example, is that many teachers just manage in English but they don't have a very high level of competence in the language, and that is problematic also for teaching subjects through the medium of English. That is a real challenge because if content teachers are going to teach through the medium of English or Catalan or Basque or another language, they need to know the content and they need to know the language but they also need to have good teaching skills and to be familiar with language and content teaching methodology, and not everybody is ready for that. There is a lot of work to be done.

Interviewer: What is the role of families in multilingual education?

Jasone Cenoz: Families play a very important role. When we look at countries where there is a high level of proficiency in different languages, it is in many cases because parents also speak those languages or perhaps because they go abroad more often on holiday or because they have more contact with foreigners, for example. That is, they have a positive attitude towards speaking different languages. This is not that easy to change but families can contribute to improving their children's level of knowledge in foreign languages or in the languages of their community. They can do a lot and when we think of leisure time, for example, or when we think about television or computer games, the Internet... There is a lot that can be done in other languages, not only regarding the home language. 
For instance, nowadays it's very easy to get the original version of a TV programme. It implies more effort and it might be a bit more uncomfortable but it's possible to use it as a language learning resource. The same is possible in the case of computer games and different online apps, so apart from having good attitudes, which is also very important, families can help a lot when it comes to encouraging their children to get more practice with a second or a foreign language outside school. I don't think that it is done enough. It could be done a lot more.

Interviewer: Speaking about community languages, do you think multilingual education could be detrimental to the promotion and revitalisation of minority languages? Why (not)?

Jasone Cenoz: It depends. Not necessarily. It could also be positive for minority languages but it depends on the way it is done. There can be situations in which a minority language is protected, promoted, and at the same time the use of this minority language is positive for learning additional languages. There are other situations in which English or another language is given as a choice. That is, learners either go on learning the minority language or they choose English and that is wrong, of course, because those languages become mutually exclusive in the educational system. Then, it is possible to promote and protect minority languages in the context of multilingual education but it is also true that it doesn't happen all the time.

Interviewer: What measures could be adopted to foster multilingualism in education? Does it depend on teachers and policy makers?

Jasone Cenoz: I think that there is a lot which can be done at different levels. Of course teachers and policy makers are extremely important. Policy makers can open the possibilities of having different types of curricula and determine the weight of languages in the curriculum. Then, Teacher Education, in-service teachers, the materials they use, their level of motivation, their command of the language or their pedagogical knowledge are also extremely important. However, I think that it is also important to recognise the ways in which students can make a contribution as well. We tend to think that it is the teacher that has to give everything to the students without realising that students themselves can contribute a lot to their own learning process and that they are already emergent multilinguals. They have their own experience and if we teach languages and we link that to their own experience they will be more motivated and they can use their own resources to a better extent than if we just think of them as containers where we just throw our knowledge.

Interviewer: In the past few years, translanguaging has raised the interest of sociolinguists and educators. Is translanguaging the key to consolidating multilingual education?

Jasone Cenoz: Translanguaging is very important and very fashionable and it is used in different ways. It started as a pedagogical technique used in bilingual education in Wales where there is a minority language, Welsh, and English. There is also a third language but it was applied with those two languages. The idea was that input and output could happen in different languages. For example, if students were watching a video about geography in English, then they had to discuss it and write a report in Welsh. And it came about because they thought that this was better because students get the terminology and communicative aspects in both languages. It started there and it has been used a lot since then. 
Ofelia García is usually associated with translanguaging. She adapted it in the context of Spanish-English bilinguals in the United States and she looked at translanguaging from a sociological perspective, a sociolinguistic perspective, and also a pedagogical one. Nowadays you can see it mainly in two different ways. One is a more spontaneous translanguaging type; bilinguals, multilinguals can use their own resources and linguistic repertoire, which includes the languages they use, and they can communicate using resources that often monolingual speakers cannot use. This is the way they communicate, a legitimate way, and this is the line that we see in many of the studies going in that direction. You can also look at translanguaging from a more pedagogical perspective in terms of how learners make use of their linguistic repertoire to learn and use languages or how teachers can draw on learners' resources to teach them foreign languages.

Interviewer: Could you provide an example?

Jasone Cenoz: When we teach students to write a composition in English, they probably have written compositions in other languages. Translanguaging can help us to see how they transfer the knowledge that they already have from one language to another. This may include learning vocabulary or the study of cognates; if we want to improve our students' level of vocabulary but we take as a point of departure words which they already know in other languages that they speak and we ask them to compare those to the new words because they belong to the same family and they have the same origin, then they can make more progress because they are linking something that they know to something that they are learning. So in these cases what we are doing is to use the students' resources as we go across languages, translanguaging, but at this level; not in a spontaneous way but rather in a pedagogical manner to see how multilingual speakers use the resources they know in one language to reinforce their other languages.

This can be done in many ways in order to help learners develop metalinguistic awareness based on the knowledge of languages which they already have. There are different ways but I think in multilingual education it is crucial to understand that that we cannot isolate languages as if the other languages didn't exist. That doesn't make sense. We have to take all languages into account and we have to look at students as multilingual speakers or at least as emergent multilinguals who bring their resources, their repertoire, into the classroom when they are learning and using an additional language.

Interviewer: So it is important to continue doing research in that direction.

Jasone Cenoz: Yes, it is extremely important to see if we consider students to be multilingual speakers and we don't look at languages as completely isolated from each other. We need to do a lot of research and to see what makes sense, what is better for the students. We need evidence comparing both approaches, the one of linguistic isolation and the one in which the speakers' whole linguistic repertoire is taken into account, and where we focus more on multilingualism and not on using one language at a time.

Interviewer: Thank you for sharing your insights, Dr. Cenoz.

Jasone Cenoz: Thank you. 


\title{
References
}

Cenoz, J. (2009). Towards multilingual education. Bristol: Multilingual Matters.

Cenoz, J. \& Gorter, D. (Eds.). (2015). Multilingual education: Between language learning and translanguaging. Cambridge, UK: Cambridge University Press

\begin{abstract}
Author information: Núria Hernández-Castillo is a teacher educator and a researcher at the Faculty of Education at the Universitat Internacional de Catalunya, Barcelona (Spain), where she teaches advanced English courses, English language teaching, and intercultural development. She coordinates a minor in English language teaching, a postgraduate degree in teaching English as a third language, and she is also a member of the Practicum Committee. At present she is conducting research on storytelling, learning-service projects, and student teachers' oral communicative skills. She is currently completing her $\mathrm{PhD}$ on teacher cognition and the role of beliefs in novice foreign language teachers at the University of the Basque Country.
\end{abstract}

Email: nhernandez@uic.cat

To cite this article:

Hernández-Castillo, N. (2015). An interview with Dr. Jasone Cenoz on multilingual education and translanguaging. Bellaterra Journal of Teaching \& Learning Language \& Literature, 8(4), 88-92.

DOI: http://dx.doi.org/10.5565/rev/jtl3.658 